\title{
Where Do You Want to Spend Your Last Days of Life? Low Concordance Between Preferred and Actual Site of Death Among Hospitalized Adults
}

\author{
Stacy Fischer, MD¹, Sung-Joon Min, PhD², Lilia Cervantes, MD³, Jean Kutner, MD, MSPH'1
}

${ }^{1}$ Division of General Internal Medicine, University of Colorado Denver School of Medicine, Denver, Colorado; ${ }^{2}$ Division of Health Care Policy and Research, University of Colorado Denver School of Medicine, Denver, Colorado; ${ }^{3}$ Denver Health and Hospital Authority, Denver, Colorado.

BACKGROUND: Death in the U.S. frequently occurs in institutions despite the overwhelming majority of persons who state that they prefer to die at home. Little research to date has examined how well individual preferences compare to actual site of death.

OBJECTIVES: Determine the concordance between preferred and actual place of death and examine independent predictors for concordance.

DESIGN: Observational cohort study.

SETTING: Three area hospitals including a safety net hospital, veterans' hospital, and academic tertiary referral center.

PATIENTS: 458 adult patients admitted to the general medical service from 2003-2005.

MEASUREMENTS: Patients were asked where they preferred to spend their last days of life. Data on date and actual site of death from 2005-2009 was collected from hospital records and death certificates.
RESULTS: The majority of patients preferred to die at home $(75 \% \mathrm{n}=343)$. Low income and being married were significantly associated with a preference to die at home compared to nursing home or inpatient hospice (OR $2.7195 \% \mathrm{Cl} 1.30-5.67$ and OR $2.4495 \% \mathrm{Cl} 1.14-5.21$ respectively). Of the 123 patients who died during the follow up period, most $(66 \% \mathrm{n}=80)$ died in an institutional setting. Overall concordance between preferred and actual site of death was only $37 \%(n=41)$. Female gender was significantly associated with concordance between preferred and actual site of death (OR 3.30 95\% Cl 1.25-8.72).

CONCLUSIONS: Concordance between preferred and actual site of death is low and female gender was the sole patient level variable associated with concordance. Journal of Hospital Medicine 2013;8:178-183. (C) 2013 Society of Hospital Medicine
At the turn of the 20th century, most deaths in the United States occurred at home. By the 1960s, over $70 \%$ of deaths occurred in an institutional setting, reflecting an evolution of medical technology. ${ }^{1-3}$ With the birth of the hospice movement in the 1970s, dying patients had the opportunity to have both death at home and aggressive symptom control at the end of life. Although there has been a slow decline in the proportion of deaths that occur in the hospital over the past 2 decades, ${ }^{3}$ the overwhelming majority of persons state that they would prefer to die at home. However, recent findings suggest that most people will die in an institutional setting. ${ }^{3-6}$

Although good data exist describing population preferences for location of death, and we know, based on death records, where deaths occur in the United States, there are few studies that examine concordance between preferred and actual site of death at the individual patient level. Furthermore, although factors

*Address for correspondence and reprint requests: Stacy Fischer, MD, Division of General Internal Medicine, Academic Office 1, General Internal Medicine, 8th Floor, 12631 East 17th Ave., Aurora, CO 80045; Telephone: 303-724-2406; E-mail: stacy.fischer@ucdenver.edu

Additional Supporting Information may be found in the online version of this article.

Received: September 19, 2012; Revised: November 29, 2012; Accepted: January 3, 2013

2013 Society of Hospital Medicine DOI 10.1002/jhm.2018

Published online in Wiley Online Library (Wileyonlinelibrary.com). have been identified that predict death at home, factors predicting concordance between preferred and actual site of death are not well described. ${ }^{3,6-13}$

Regardless of where death ultimately occurs, most adults will experience multiple hospitalizations within the last years of their life. Understanding the preferences and subsequent experiences of this population is of particular relevance to hospitalist physicians who are in a unique position to elicit goals from seriously ill patients and help match patient preferences with their medical care. In this observational study, we sought to determine preferences for site of death in a cohort of adult patients admitted to the hospital for medical illness, and then follow those patients to determine where death occurred for those who died. We also sought to explore factors that may predict concordance between preferred and actual site of death. We hypothesized that ethnic diversity and lower socioeconomic status would be associated with a lower likelihood of concordance between preferred and actual site of death. We also hypothesized that advanced care planning would be associated with a higher likelihood of concordance. The Colorado MultiInstitutional Review Board approved this study.

\section{METHODS}

Participants were recruited from 3 hospitals affiliated with the University of Colorado School of Medicine Internal Medicine Residency program, including the 
Denver Veterans' Administration Center (DVAMC), Denver Health Medical Center (DHMC), and University of Colorado Hospital (UCH). The DVAMC is a large urban Veterans Administration hospital, serving veterans from the Denver metro area, and is a tertiary referral center for veterans in rural Colorado, Wyoming, and parts of Montana. DHMC, the safety-net hospital for the Denver area, serves over $25 \%$ of the residents in the city and county of Denver, including such special populations as the indigent, chronically mentally ill, and persons with polysubstance dependence. UCH had 350 licensed beds at the time of our study and serves as the Rocky Mountain region's only academic tertiary, specialty care, and referral center. At the time of this study, there was limited inpatient palliative care services at the DVAMC and UH, and no palliative care services at DHMC. Participants were screened on the first day following admission to the adult general medical service. Participants were recruited on 96 postadmission days between February 2004 and June 2006. Recruitment days varied from Monday through Friday, to include admissions from the weekend and throughout the year to reduce potential bias due to seasonal trends of diseases such as influenza. Patients were excluded if they died or were discharged within the first 24 hours of admission, were pregnant, jailed, or unable to give informed consent. All other patients were approached and invited to participate in a brief survey.

After informed consent was obtained, participants completed a bedside interview that included self-identified ethnicity and the Berkman-Syme Social Network Index, ${ }^{14}$ a brief questionnaire quantifying social support from spouse or domestic partner, family, friends, and other religious or secular organizations. Baseline socioeconomic measures (eg, income, employment, home ownership, car ownership) and questions related to the last days of life were also included. Participants were asked the following question, "If you were very sick, with an illness that could not be cured, and in bed most of the time, where would you spend the last days of your life if you could chose?"

For each participant, we performed a detailed chart review to determine demographic data, presence of advance directives, and CARING criteria (Cancer, Admissions $\geq 2$, Residence in a nursing home, Intensive care unit admit with multiorgan failure, $\geq 2$ Noncancer hospice Guidelines), a set of prognostic criteria identifying patients at an index hospitalization who have a high burden of illness and are at risk for death in the following year. ${ }^{15}$ We then followed patients for 5 years. If participants died within the follow-up period, we collected the date and location of death using medical records, death certificates, or in a few cases when official death records were unavailable, direct contact with the family. Participants were considered alive if
TABLE 1. Baseline Characteristics $(n=458)$

\begin{tabular}{lc}
\hline Mean age ( \pm SD), y & $57.9( \pm 14.8)$ \\
\hline Mean time to death ( \pm SD), d & $339.5( \pm 348.4)$ \\
Ethnicity & \\
African American & $19 \%(88)$ \\
Caucasian & $52 \%(239)$ \\
Latino & $22 \%(102)$ \\
Other & $6 \%(29)$ \\
Spanish language only & $6 \%(27)$ \\
Female gender & $35 \%(159)$ \\
Admilted to DVAMC & $41 \%(188)$ \\
Admitted to DHMC & $38 \%(174)$ \\
Admitted to UCH & $21 \%(96)$ \\
CARING criteria & \\
Cancer diagnosis & $11 \%(51)$ \\
Admitted to hospital $\geq 2$ times in the past year for chronic illness & $40 \%(181)$ \\
Resident in a nursing home & $2 \%(9)$ \\
Noncancer hospice guidelines (meeting $\geq 2)$ & $13 \%(59)$ \\
Income $<\$ 30,000 /$ /year & $84 \%(377)$ \\
No greater than high school education & $55 \%(248)$ \\
Home owner & $26 \%(120)$ \\
Rents home & $39 \%(177)$ \\
Unstable living situation & a \\
Low social support & $34 \%(156)$ \\
Uninsured & $36 \%(165)$ \\
Regular primary care provider & $18 \%(81)$ \\
& $73 \%(330)$ \\
\hline
\end{tabular}

NOTE: Abbreviations: CARING, Cancer, Admissions $\geq 2$, Residence in a nursing home, Intensive care unit admit with multiorgan failure, $\geq 2$ Noncancer hospice Guidelines; DHMC, Denver Health Medical Center, DVAMC, Denver Veterans Affairs Medical Center; SD, standard deviation; UCH, University of Colorado Hospital.

a Unstable living situation defined as either homeless, living in shelters, or with friends.

bLow social support defined as Identifying $\leq 2$ forms of social support (spouse/significant other, relatives, friends, church or other group) present in their life. Data are presented as \% (n) unless otherwise noted.

they had a clinic visit or $\mathrm{MD} / \mathrm{RN}$ phone contact within 3 months prior to the final collection point date.

\section{Analysis}

SAS 9.1 (SAS Institute Inc., Cary, NC) was used for all analyses. Simple frequencies and means statistics were used to determine rates of descriptive characteristics of the sample as well as rates of the measured outcomes, preferred place to spend last days of life, and actual site of death. Agreement or concordance between preferred and actual site of death was calculated. For the purposes of the analysis, we assumed all persons who stated they had no preference died in a place concordant with their wishes. To calculate agreement by preferred and actual site, participants who expressed a preference and died $(n=111)$ in hospital, nursing home, home, or hospice setting were included in the analysis, and participants $(n=4)$ who died in an unknown or other locations were excluded (eg, motel room).

\section{Logistic Regression Modeling}

$\chi^{2}$ tests were performed for all categorical variables to determine a significant association with outcome variables. Preferred place of death and concordance 

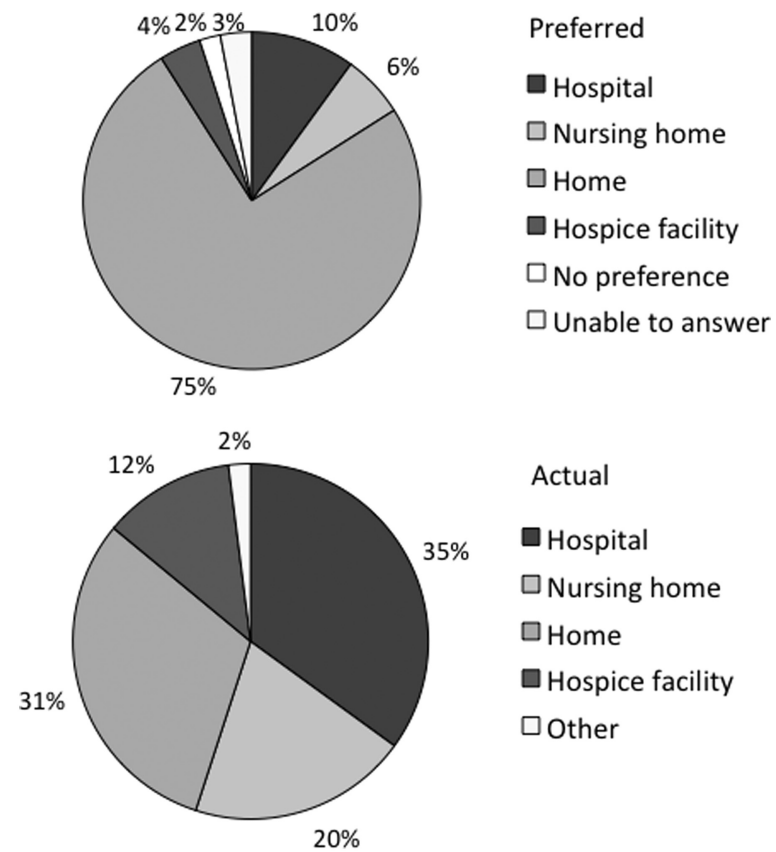

Actual

$\square$ Hospital

$\square$ Nursing home

$\square$ Home

$\square$ Hospice facility

$\square$ Other

FIG. 1. Preferred $(n=458)$ and actual $(n=121)$ site of death.

between preferred and actual site of death were modeled using predictive variables selected if univariable association demonstrated a $\mathrm{P} \leq 0.25$. This standard cutoff was selected to broadly identify candidate variables for logistic regression modeling. ${ }^{16}$ A stepwise algorithm was used to select significant predictors that would remain in the model.

In lieu of fitting a multinomial logit model for preferred site of death of home vs hospital vs nursing home or hospice facility as preferred site of death, 3 logit models (although only 2 may be sufficient to estimate the underlying multinomial logit $\operatorname{mode}{ }^{17}$ ) were considered with outcome categories: home vs nursing home or hospice facility, and hospital vs nursing home or hospice facility and home vs hospital.

For the logistic regression modeling of concordance, we included the full sample of patients who died during the follow-up period $(n=123)$. We classified participants as dying in a place concordant with their wishes or not concordant.

\section{RESULTS}

\section{Study Population}

Subjects were recruited on 96 post-admission days totaling 842 admissions. Three hundred thirty-one patients $(39 \%)$ were ineligible for study participation $(\mathrm{n}=175$ discharged within 24 hours, $\mathrm{n}=76$ unable to consent, $\mathrm{n}=78$ ineligible for other reasons [eg, prisoner, pregnant, under 18 years old], $\mathrm{n}=2$ died within 24 hours of admission). Only 53 of the remaining 511 $(10 \%)$ patients refused; 458 patients $(90 \%)$ gave informed consent to participate. Characteristics of the study population are depicted in Table 1 . There were very few missing cases $(<3 \%)$, that is persons without a recent clinic follow-up date, contact, or a confirmed
TABLE 2. Logistic Regression Modeling of Preference for Death at Home or Hospital

\begin{tabular}{lllc}
\hline \multicolumn{4}{c}{ Adjusted Odds Ratio (95\% Confidence Interval) } \\
\hline & $\begin{array}{c}\text { Home vs } \\
\text { Nursing Home/ } \\
\text { Hospice Facility }\end{array}$ & $\begin{array}{c}\text { Hospital vs } \\
\text { Nursing Home/ } \\
\text { Hospice Facility }\end{array}$ & $\begin{array}{c}\text { Home vs } \\
\text { Hospital }\end{array}$ \\
\hline Low income & $2.71(1.30-5.67)$ & $3.05(1.01-9.24)$ & $0.99(0.42-2.37)$ \\
Married & $2.44(1.14-5.21)$ & $2.40(0.87-6.62)$ & $0.82(0.42-1.57)$ \\
CARING criteria & $0.58(0.30-1.14)$ & $0.44(0.18-1.09)$ & $0.89(0.47-1.66)$ \\
\hline
\end{tabular}

NOTE: Abbreviations: CARING, Cancer, Admissions $\geq 2$, Residence in a nursing home, Intensive care unit admit with multiorgan failure, $\geq 2$ Noncancer hospice Guidelines.

TABLE 3. Concordance by Site of Preferred and

Actual Site of Death With a Preferred Site $(n=111)$

\begin{tabular}{lccccc}
\hline & \multicolumn{4}{c}{ Actual Site of Death, n (Row \%) } & \\
\cline { 2 - 5 } & \multicolumn{3}{c}{ Nursing } & Hospice & Row Total, \\
& Hospital & Home & Home & Facility & Out of 111 \\
\hline Preferred hospital & $5(42 \%)$ & $3(25 \%)$ & $2(17 \%)$ & $2(17 \%)$ & $12(11 \%)$ \\
Preferred nursing home & $1(13 \%)$ & $5(63 \%)$ & $2(25 \%)$ & 0 & $8(7 \%)$ \\
Preferred home & $30(34 \%)$ & $15(17 \%)$ & $31(35 \%)$ & $12(14 \%)$ & $88(79 \%)$ \\
Preferred hospice facility & $3(100 \%)$ & 0 & 0 & 0 & $3(3 \%)$ \\
\hline
\end{tabular}

date of death. These persons were considered alive. Overall, the sample population was ethnically diverse, slightly older than middle age, mostly male (due to the inclusion of the Veterans Administration hospital), and of low socioeconomic status.

\section{Preferred Site of Death}

When asked where they preferred to spend the last days of their life, $75 \%$ of patients $(n=343)$ stated they would like to be at home. In the hospital was the preferred location for $10 \%$ of patients, whereas $6 \%$ stated a nursing home and $4 \%$ a hospice inpatient facility. Two percent stated they had no preference, and $3 \%$ refused to answer (Figure 1)

We found that in the univariable analysis the following factors were associated with preference for site of death at a significance level of $\mathrm{P}<0.25$ : unstable housing, hospital setting, income level, ethnicity, CARING criteria, presence of an advance directive, education level, married, primary care provider, and presence of public insurance. Results of the logit models (home vs nursing home or hospice facility, and hospital vs nursing home or hospice facility and home vs hospital) are presented in Table 2 .

Patients with income $<\$ 30,000 /$ year were more likely to prefer home (or hospital) over a nursing home or hospice facility. Being married was predictive of preferring home over nursing home or hospice facility. Patients meeting $\geq 1$ of the CARING criteria trended toward being less likely $(\mathrm{P}=0.11$ for home and $\mathrm{P}=0.08$ for hospital) to prefer home (or hospital) vs nursing home or hospice facility. However, there were no significant predictors for a preference for 
TABLE 4. Predictors of Concordance Between Preferred and Actual Site of Death

\begin{tabular}{lccl}
\hline & \multicolumn{3}{c}{ Adjusted Odds Ratio (95\% Confidence Interval) } \\
\hline & All & $\begin{array}{c}\text { Home (Using } \\
\text { Same Variables) }\end{array}$ & $\begin{array}{c}\text { Home (Using Only } \\
\text { Significant Variables) }\end{array}$ \\
\hline Female gender & $3.30(1.25-8.72)$ & $4.62(1.44-14.79)$ & $3.57(1.24-10.34)$ \\
CARING criteria & $3.09(0.97-9.81)$ & $7.72(1.67-35.71)$ & $5.93(1.41-24.91)$ \\
Latino vs African & $0.43(0.15-1.24)$ & $0.35(0.09-1.30)$ & \\
American/Caucasian/other & & &
\end{tabular}

NOTE: Abbreviations: CARING, Cancer, Admissions $\geq 2$, Residence in a nursing home, Intensive care unit admit with multiorgan failure, $\geq 2$ Noncancer hospice Guidelines.

home or hospital when directly comparing the 2 locations, as expected from observing similar effects of variables in the other 2 logit models.

\section{Actual Site of Death}

One hundred twenty-three patients died during the follow-up period ( $26 \%$ of the total sample). Of those who died, the mean age was 64 years (standard deviation \pm 13 ), $82 \%$ had annual incomes $<\$ 30,000,73 \%$ were men, and $77 \%$ met at least 1 of the CARING criteria suggesting advanced medical illness. The distribution of ethnicities of the deceased subsample was similar to that of the overall cohort. Complete death records were obtained for 121 patients. Only 31\% $(\mathrm{n}=38)$ died at home, whereas $35 \%(\mathrm{n}=42)$ died in a hospital, $20 \%(n=24)$ died in a nursing home, and $12 \%(\mathrm{n}=14)$ died in an inpatient hospice facility (Figure 1).

In univariable analysis, there were no associations at a $25 \%$ significance level between actual site of death and ethnicity, gender, age, severity of illness, high vs low social support, high or low socioeconomic status, stable vs unstable housing, or presence of a completed advance directive in the medical record.

\section{Concordance Between Preferred and Actual Site of Death}

Overall, $37 \%$ of the patients died where they stated they would prefer to die, including the 2 with no preference. Concordance rates for each site of death are presented in Table 3. We examined sociodemographic variables, disease severity, advance-care planning, primary care provider, health insurance, and hospital site to look for associations with concordance. We found that female gender was positively associated with concordance (odds ratio [OR], 3.30; 95\% confidence interval $[\mathrm{CI}], 1.25-8.72)$. CARING criteria $(\mathrm{P}=0.06)$ and Latino ethnicity (vs all other ethnicity categories, $\mathrm{P}=0.12$ ) also showed trends for association. Restricting to those who preferred home, the associations became stronger (OR, 4.62; 95\% CI, 1.44-14.79 for female; OR, 7.72; 95\% CI, 1.67-35.71 for CARING criteria), and the trend for the negative association between Latino ethnicity and concordance remained $(\mathrm{P}=0.12)$. Results of the model are shown in Table 4 .

\section{DISCUSSION}

We found, similarly to previous reports in the literature, the majority of patients preferred to die at home. We did not find a significant difference in preferences or location of death by ethnicity or illness severity. Lower-income patients and married patients were more likely to prefer to be at home over a nursing home or a hospice facility in the last days of life. We found that the minority of patients died at their stated preferred site of death, and female gender was the only predictive variable we found to distinguish those patients who died in a place concordant with their wishes compared to those who did not.

In the literature, previous studies have reported concordance rates between preferred and actual site of death that range from $30 \%$ to $90 \% .^{12,13,18-24} \mathrm{We}$ found a concordance rate at the lowest end of this spectrum. In trying to understand our findings and place them in context, it is helpful to examine other studies. Many of these studies focused solely on cancer patients. ${ }^{13,18-23}$ Cancer follows a more predictable trajectory of decline compared to other common lifethreatening illnesses, such as cardiac disease, emphysema, or liver failure, that often involve periods of acute deteriorations and plateaus throughout illness progression. The more predictable trajectory may explain the overall higher concordance rates found in the studies involving cancer patients.

The majority of studies in the literature examining concordance between preferred and actual site of death recruited the study sample from home health or home palliative care programs that were providing support and care to participants. ${ }^{10,12,13,18,22,25-27}$ The high concordance rates reported may be the result of the patients in the sample receiving services at home aimed at eliciting preferences and providing support at home. Our observational study is unique in that we elicited patient preferences from a diverse group of hospitalized adults. Patients had a broad range of medical illness and were at various stages in their disease trajectory. This allowed our findings to be more generalizable, a major strength of our study.

The only variable associated with concordance that we identified to predict concordance between preferred and actual site of death was female gender. Women have been shown to be more active in medical decision making, which may explain our findings. ${ }^{28}$ Female gender and illness severity (as measured by the CARING criteria) were found to be associated with concordance when the preference is for death at home. For persons with more advanced medical illness, they may have had more opportunity to consider their preferences and talk about these preferences. It is even possible that our interview prompted some participants to have discussions with their families or providers.

Variables with high face validity, such as high social support, higher education, and completing an advance directive, did not demonstrate any effect on the 
outcome of concordance. Other studies have shown that low functional status, Caucasian ethnicity, home care, higher education, and social support have been associated with a greater likelihood for a home death. 3,6,9 However, although studies specifically examining concordance between preferred and actual site of death have looked at predictors for home death, we were unable to find predictors for concordance across all preferences in the literature. We can conclude from our findings that the factors that influence concordance of preferences for site of death are extremely complex and difficult to capture and measure. This is extremely unsatisfying in the face of the low concordance rate of $30 \%$ we identified.

Latino ethnicity showed a trend toward having a negative association with concordance between preferred and actual site of death. This trend persisted whether it was concordance overall or for concordance with those who preferred a death at home. In the literature, Latinos have been found to be less likely to complete advance directives, use hospice services at the end of life, and are more likely to experience a hospital death. ${ }^{29-33}$ As care at the end of life continues to improve, careful attention should be paid to ensure that these kinds of gaps do not widen any further.

We interviewed patients at an index hospitalization. Patients had an acute medical illness or an exacerbation of a chronic medical illness and required at least 24 hours of hospitalization to be eligible for inclusion. Our bedside interview made use of an opportune time to question patients, a time when it may have been easier for patients to visualize severe illness at the end of life, rather than asking this question during a time of wellness. Although participants overwhelmingly stated they preferred to be at home, for those who died, decisions were made in their care that did not allow for this preference.

Our follow-up after the initial bedside interview only included death records of where and when participants died. We do not have the details and narrative of the conversations that may have taken place that led to the care decisions that determined participants' actual place of death. We do not know if preferences were elicited or discussed, and care decisions then negotiated, to best meet the goals and preferences expressed at that time. We also do not know if the conversations did not occur and the default of medical intervention and cure-focused care dictated how participants spent the last days of their life. There is evidence that when conversations about goals and preferences do occur, concordance between preferences and care received are high. ${ }^{12,21}$

We were unable to identify any predictors beyond gender in this cohort of adults hospitalized with a broad spectrum of severe medical illness to predict concordance with stated preferences and actual site of death. We can conclude then, based on our findings and supported by the literature, that the default trends toward institutional end-of-life experiences. To shift to a more patient-centered approach, away from the default, healthcare providers need to embrace a palliative approach and incorporate preferences and goals into the discussions about next steps of care to facilitate the peaceful death that the majority of patients imagine for themselves. Hospitalist physicians have a unique opportunity at an index hospitalization to start the conversation about preferences for care including where patients would want to spend the last days of their life.

Our study does have some limitations. We elicited preferences at a single point in time, at an index hospitalization. It is possible that participants' preferences changed over the course of their illness. However, in Agar et al.'s study of longitudinal patient preferences for site of death and place of care, most preferences remained stable over time. ${ }^{18}$ We also did not have data that included palliative care involvement, homecare or hospice utilization, or cause of death. All of these variables may be important predictors of concordance. Issues of symptom management and lack of caregiver may also dictate place of death, even when goals and care are aligned. We do not have data to address these components of end-of-life decision making.

\section{CONCLUSION}

Patients continue to express a preference for death at home. However, the majority of patients experienced an institutional death. Furthermore, few participants achieved concordance with where they preferred to die and where they actually died. Female gender was the sole factor associated with concordance between preferred and actual site of death. Incorporating a palliative approach that elicits goals and helps match goals to care, may offer the best opportunity to help people die where they chose.

Disclosures: This research was supported by the Brookdale National Fellowship Award and the NIA/ Beeson grant 5K23AG028957. All authors have seen and agree with the contents of the article. This submission was not under review by any other publication. The authors have no financial interest or other potential conflicts of interest.

\section{References}

1. Field MJ, Cassel CK, eds. Committee on Care at the End of Life. Approaching Death: Improving Care at the End of Life. Washington DC: National Academy Press; 1997.

2. Brock DB, Foley DJ. Demography and epidemiology of dying in the U.S. with emphasis on deaths of older persons. Hosp J. 1998;13:4960.

3. Weitzen S, Teno JM, Fennell M, Mor V. Factors associated with site of death: a national study of where people die. Med Care. 2003;41:323-335.

4. Townsend J, Fermont D, Dyer S, Karran O, Walgrove A, Piper M. Terminal cancer care and patient's preferences for place of death: a prospective study. BMJ. 1990;301:415-417.

5. Pritchard RS, Fisher ES, Teno JM, et al. Influence of patient preferences and local health system characteristics on the place of death. SUPPORT Investigators. Study to Understand Prognoses and Preferences 
for Risks and Outcomes of Treatment. I Am Geriatr Soc. 1998;46:1242-1250.

6. Gruneir A, Mor V, Weitzen S, Truchil R, Teno J, Roy J. Where people die: a multilevel approach to understanding influences on site of death in America. Med Care Res Rev. 2007;64:351-378.

7. Cohen J, Bilsen J, Hooft P, Deboosere P, van der Wal G, Deliens L. Dying at home or in an institution using death certificates to explore the factors associated with place of death. Health Policy. 2006;78:319-329.

8. Karlsen S, Addington-Hall J. How do cancer patients who die at home differ from those who die elsewhere? Palliat Med. 1998;12:279-286.

9. Gomes B, Higginson IJ. Factors influencing death at home in terminally ill patients with cancer: systematic review [published correction appears in BMJ. 2006;332:1012]. BMJ 2006;332:515-521.

10. Gyllenhammar E, Thoren-Todoulos E, Strang P, Strom G, Eriksson E, Kinch M. Predictive factors for home deaths among cancer patients in Swedish palliative home care. Support Care Cancer. 2003;11:560567.

11. Gyllenhammar E, Nordfors LO. Systemic adenosine infusions alleviated neuropathic pain. Pain. 2001;94:121-122.

12. Leff B, Kaffenbarger KP, Remsburg R. Prevalence, effectiveness, and predictors of planning their place of death among older persons followed in community-based long term care. I Am Geriatr Soc. 2000;48:943-948.

13. Brazil K, Howell D, Bedard M, Krueger P, Heidebrecht C. Preferences for place of care and place of death among informal caregivers of the terminally ill. Palliat Med. 2005;19:492-499.

14. Berkman LF, Syme SL. Social networks, host resistance, and mortality: a nine-year follow-up study of Alameda County residents. Am J Epidemiol. 1979;109:186-204.

15. Fischer SM, Gozansky WS, Sauaia A, Min SJ, Kutner JS, Kramer A. A practical tool to identify patients who may benefit from a palliative approach: the CARING criteria. J Pain Symptom Manage. 2006;31:285-292.

16. Hosmer DW, Lemeshow S. Applied Logistic Regression. 2nd ed. New York, NY: Wiley-Interscience; 2000.

17. Begg CB, Gray R. Calculation of polychotmous logistic regression parameters using individualized regressions. Biometrika. 1984;71:1118.

18. Agar M, Currow DC, Shelby-James TM, Plummer J, Sanderson C, Abernethy AP. Preference for place of care and place of death in palliative care: are these different questions? Palliat Med. 2008;22(7):787795.

19. Thomas C, Morris SM, Clark D. Place of death: preferences among cancer patients and their carers. Soc Sci Med. 2004;58:2431-2444.
20. Tang ST, McCorkle R. Determinants of congruence between the preferred and actual place of death for terminally ill cancer patients. $J$ Palliat Care. 2003;19:230-237.

21. McWhinney IR, Bass MJ, Orr V. Factors associated with location of death (home or hospital) of patients referred to a palliative care team. CMAJ. 1995;152:361-367.

22. Bakitas M, Ahles TA, Skalla K, et al. Proxy perspectives regarding end-of-life care for persons with cancer. Cancer. 2008;112:18541861.

23. Beccaro M, Costantini M, Giorgi Rossi P, Miccinesi G, Grimaldi M, Bruzzi P. Actual and preferred place of death of cancer patients. Results from the Italian survey of the dying of cancer (ISDOC). J Epidemiol Community Health. 2006;60:412-416.

24. Tolle SW, Tilden VP, Rosenfeld AG, Hickman SE. Family reports of barriers to optimal care of the dying. Nurs Res. 2000;49:310-317.

25. Thomas C, Morris SM, Clark D. Place of death: preferences among cancer patients and their carers. Soc Sci Med. 2004;58(12):24312444.

26. Groth-Juncker A, McCusker J. Where do elderly patients prefer to die? Place of death and patient characteristics of 100 elderly patients under the care of a home health care team. I Am Geriatr Soc. 1983;31:457-461.

27. Cantwell P, Turco S, Brenneis C, Hanson J, Neumann CM, Bruera E. Predictors of home death in palliative care cancer patients. I Palliat Care. 2000;16:23-28.

28. Arora NK, McHorney CA. Patient preferences for medical decision making: who really wants to participate? Med Care. 2000;38:335341.

29. Smith AK, McCarthy EP, Paulk E, et al. Racial and ethnic differences in advance care planning among patients with cancer: impact of terminal illness acknowledgment, religiousness, and treatment preferences. J Clin Oncol. 2008;26:4131-4137.

30. Romero LJ, Lindeman RD, Koehler KM, Allen A. Influence of ethnicity on advance directives and end-of-life decisions. JAMA. 1997;277: 298-299.

31. McKinley ED, Garrett JM, Evans AT, Danis M. Differences in end-oflife decision making among black and white ambulatory cancer patients. J Gen Intern Med. 1996;11:651-656.

32. Greiner KA, Perera S, Ahluwalia JS. Hospice usage by minorities in the last year of life: results from the National Mortality Feedback Survey. I Am Geriatr Soc. 2003;51:970-978.

33. Wright AA, Keating NL, Balboni TA, Matulonis UA, Block SD, Prigerson HG. Place of death: correlations with quality of life of patients with cancer and predictors of bereaved caregivers' mental health. J Clin Oncol. 2010;28:4457-4464. 